\title{
THE GROWTH OF PHONEMIC AND LEXICAL PATTERNS IN INFANT LANGUAGE
}

\author{
H. V. VELTEN \\ INDIANA UNIVERSITY
}

[See the first and the last paragraph.]

This study is based on a record of my daughter Joan's speech from her eleventh to her thirty-sixth month. ${ }^{1}$ It will deal chiefly with phonemic and lexical matters. For, apart from other reasons which will be discussed below, the morphological and syntactical development in the language of English-speaking children has been well described in numerous works, while only two authors have hitherto been concerned, implicitly or explicitly, with problems of phonemics in infant language, ${ }^{2}$ and as regards vocabulary patterns, it is impossible to glean any information from the customary alphabetical word lists. ${ }^{3}$

In a multitude of books on infant language it has been established that the acquisition of language properly speaking is preceded by a period, called 'babillage' (by H. Delacroix), 'Lallperiode' (by K. Bühler), or babbling stage, during which the speech organs are developed and incessantly exercised. Even the most outlandish sounds, i.e. speech sounds which the child has certainly never heard, may be produced and perfectly articulated during this time. An American child may pronounce velar spirants, voiceless nasals, retroflex sibilants, etc. During the early stages a uvular $r$ is quite common. ${ }^{4}$ Joan was particularly addicted ( $3 \mathrm{~d}$ to 8 th) to velar $g$-sounds and to voiceless palatal spirants. ${ }^{5}$

At the end of this stage, i.e. with the first appearance of phonemes, the ability to produce a multitude of speech sounds seems to vanish overnight. ${ }^{6}$ However,

1 The month during which a given linguistic form was acquired will be referred to by an ordinal number in parentheses.

${ }^{2}$ Cf. A. Grégoire, Bibliothèque de la Fac. de Philos. et Lettres de l'Univ. de Liège (1937) and R. Jakobson, Språkvetenskapliga Sällskapets i Uppsala Förhandlingar 1940-2,1-83. Jakobson has gathered all the evidence that can be gleaned indirectly from other works and gives an exhaustive general bibliography (78-83).

${ }^{3}$ Cf. W. v. Wartburg, Mél. Charles Bally 11 (Geneva, 1939): 'Es wird nie möglich sein, das Wesen des Sprachschatzes ... zu erfassen, solange nicht die alphabetische Reihenfolge ersetzt wird durch ein der Sprache in ihrem jeweiligen Zustand selbst abgelauschtes Darstellungssystem.'

${ }^{4}$ Cf. A. Grégoire, Journal de Psychol. 30.376-8 (1933).

${ }^{5}$ During this period, sound may of course be used in a purely expressive function, e.g. to indicate pleasure or displeasure. The following two utterances carried over from the babbling stage survived in Joan's speech: (1) ñañaña expresses annoyance; it disappears as soon as $n u$ 'no' is acquired (22d); (2) $\tilde{e}$ (pronounced like French hein or the similar interrogative sound often heard in English) is used in response to question to show delight at being the centre of interest; it turns into $a$ ' 'yes' (19th), which is later used as an emphatic or contradictory affirmative particle (like French $s i$ ), after the variants $h a \cdot, u \cdot h u$. 'yes' (22d) have been developed.

${ }^{6}$ A period of complete silence sometimes intervenes between the babbling stage and the acquisition of language; cf. E. Meumann, Die Sprache des Kindes 23 (Zurich, 1903); Jakobson 16. 
it is of course not a physical ability that has disappeared. The use of distinctive sounds is at first severely restricted because a child does not acquire a phoneme system by random selection or by taking it over ready-made from the language of the adults, but by proceeding, step by step, from the greatest possible phonemic distinction to smaller and smaller differentiations. This process is identical for children of all linguistic communities. ${ }^{7}$ That is to say, the relative chronology is the same, although the absolute time-scale varies considerably. For some children have acquired the standard phonological system of their parents' speech at the age of eighteen months, ${ }^{8}$ while others of equal mental and physical ability do not pronounce certain phonemes until they are six years old or even older. ${ }^{9}$ As regards Joan's speech, the growth of the phoneme pattern appears to have been comparatively slow, whereas the expansion of her vocabulary has been relatively rapid ${ }^{10}$ (a combination which accounts for the occurrence of an unusually large number of homonyms; see below).

The order in which the first six phonemes (comprising 15 phonemic oppositions) appear in infant language is the following. ${ }^{11}$ (1) The basic pair of phonemes consists of a vowel (usually of the widest opening) and a consonant which is produced by a complete closure of the oral and nasal cavities. (2) The subsequent, and ever narrowing, phonemic distinctions arise through the addition of (a) a continuant, i.e. a sound halfway between a vowel and a stop, (b) a second stop sound, (c) a second continuant, and (d) a second vowel. The two continuants are either the nasals $m$ and $n$ or, more rarely, a sibilant and a labial spirant. The first pair of stops is, of course, $p-t$. The second vowel, which is either $i$ or $u$, does not appear until this quadrangular system of consonant oppositions has been established, namely (1) ${ }_{t}^{p m}{ }_{n}$ or (2) ${ }_{i s}^{p f} .12$

Joan's speech has the initial pattern (2). Her first words, in chronological sequence, are, (end of 11th) ap 'up', ba 'bottle, bang'; (12th) bas '(omni)bus, box', $b a^{\cdot} ' z a$, later $b a z a^{\prime}$ 'put on', $z a$ 'that' (demonstrative or deictic particle); (13th) $d a$ 'down', at 'out', $b a^{\circ}$ 'ba 'away, outside', bat 'pocket'; (14th) af, which after assiduous practice changes to faf 'Fuff' (the name of the family cat), bada' (replaces baza'); (15th) bus 'push', uf 'dog' ('woof'), ba. 'pie'; (16th) dat 'duck', bap ${ }^{13}$ 'lamb'; (17th) am 'cereal' (i.e. the capital letter M, which the child

${ }^{7}$ There is ample evidence concerning European children (in the territory of Germanic, Romance, Slavic, and Finno-Ugrian languages), as well as American Indian and Japanese children; cf.Jakobson 32.

${ }^{8}$ Cf. Grammont's remark about his children in a letter quoted by L. Ronjat in Le développement du langage observé chez un enfant bilingue 57 (Paris, 1913).

${ }^{9}$ See Ronjat 58; Jakobson 33.

${ }^{10}$ The average number of words a normal child knows at a given age is of ten quoted in popular works on child psychology. But such figures are all but meaningless because of the enormous individual variation.

${ }^{11}$ Cf. Jakobson 37, and the same author's paper in Ve Congr. Intern. des Linguistes, Résumés des communications 28 (Bruges, 1939).

${ }^{12}$ In this paragraph I have restated Jakobson's observations in terms which do not alter his basic principle, but take into account a larger measure of initial variation than he allowed for.

${ }^{13} \mathrm{~A}$ word invented by the child when looking at a picture of a lamb. Since it was adopted by the adults of the household it persisted for many months until it was replaced by $z a \cdot b$ (27th). 
first discovered on a box of cereal), an ' $\mathrm{N}$ ', n (later $u$ n) 'in'; (18th-20th) $d a$. 'doll', as ' $\mathrm{S}$ ', $u$ ' $\mathrm{O}$ ' (or anything ring-shaped, e.g. a tire), $a$ ' $\mathrm{R}$ ', nas 'nice', $n a$ ' $n a$ 'banana'; (21st) wa' ' $\mathrm{Y}$ ', ats ' $\mathrm{X}$ ', $d u^{\prime} d u$ 'Doudou' (character in a French children's tale; used later as the name of a doll), hwut 'foot'. Note that-like $p$ and $b, s$ and $z, t$ and $d-h w$ (a strongly aspirated $w$-sound) and $f$ are allophones of one phoneme, the voiceless form being used in final position only. ${ }^{14}$ Initial $f$ appears at first only in words which also end in $f$ : faf 'cat' and (22d) $f u f$ 'fish' (with $-f$ for $-s$ by assimilation). During the latter part of the $22 \mathrm{~d}$ month, however, $h w$ - changes to $f$, and henceforth $f$ occurs in all positions.

The small number of morphemes employed so far is entirely out of proportion with the enormous linguistic effort actually expended by the child. The acquisition of the initial vocabulary can be divided into the following (partly overlapping) stages..$^{15}$

(1) The first words are used to accompany action or to call for action. Thus $a p$ 'up' (used before the child could walk) signifies 'I am standing up' or 'I want to change my position', 'I want to be taken out of here'; $b a$ 'bottle, cup' means e.g. 'I want my milk' or 'I am having my orange juice'; baza' 'put on' is a peremptory command to put the lid on the sugar bowl; bas calls attention to a passing bus or expresses a desire to see cars go by ${ }^{16}$ etc.

(2) The $b a-b a d a^{\prime}$ stage, as it may be called, accompanies the unceasing practice of co-ordinating hand and eye. Everything that can be handled is divided into (a) movable parts that may be joined together, such as boxes with hinged covers, doors and books to be slammed shut, napkins and papers that can be folded over, coats that are to be buttoned, and all kinds of fasteners like buckles, snaps, safety pins, or zippers; and (b) detached parts to be experimented with, which may turn out to have a natural affinity (such as saucepans and lids, cups and saucers, etc.) or not (e.g. shoes and pencils, lamps and ash-trays). Process (a) is called $b a$, process (b) $b a d a^{\prime}$ (if successful). This habit does not come to an end until most of the functions of $b a$ are taken over (22d) by $z a t$ 'shut', bat 'button, buckle', and nap 'snap'. $\quad b a$ is last heard (30th) in reference to the closing of a safety pin. buda' $\left(<b a d a^{\prime}\right)$ disappears when an 'on' has become firmly established (23d).

(3) The deictic or $z a$ stage is a period of incessant linguistic effort (14th-22d). The child will point to an object, saying $z a$; then, upon being told that it is, e.g., a clock, she will take me by the hand and insist on inspecting every timepiece in the house and on having the name repeated before each one. She does not use the name herself, but her response to questions or requests shows that she remembers them very well-until, toward to end of this stage she suddenly blossoms out with a large active vocabulary. For a considerable time thereafter, she responds to new words elicited by $z a$ with an insistent $m u$ ' 'more', i.e. a

\footnotetext{
${ }^{14}$ Although many children use at first only voiceless oral consonants, this initial phonetic variation of voiced and voiceless sounds is by no means uncommon. Cf. W. F. Leopold's record of his daughter's vocabulary in Speech Development of a Bilingual Child (Northw. Univ. Studies in the Humanities VI, 1939), which lists voiceless finals, but almost no voiceless initials, except for some interjections.

${ }^{15}$ I wish to emphasize that these stages are based on observations of linguistic behavior. They are not intended to present any psychological or logistic theories whatsoever.

16 bas does not occur in reference to a stationary car until a later stage.
} 
demand for more specimens of the same object or being. This process of linguistic identification has been described in many works on infant language. It means simply that the visual world of lights, shadows, and colors, surfaces, angles, and outlines is being sorted out into objects by means of language. At first, the child is not at all interested in finding out what the objects with which she is becoming familiar are used for. ${ }^{17}$ Nor is there the slightest difference in her reaction to inanimate objects as compared to living beings. (For many months, by the way, $z a$ refers to persons as well as things, and fat [22d] represents 'what' and 'who'-although the child understands who and would have no difficulty in pronouncing it.)

(4) The stage of classification (22d ff.), (a) by identifying objects with the persons who use them, (b) by size, (c) by color, and (d) by opposites, involves intricate and overlapping vocabulary patterns (to be described in a separate paper). Stage 4 is characterized by the great frequency of paratactic duplicate statements, such as (23d) za nu' but wut du-za zua dud du' bu 'that (is) no big red chair, that (is a) little green table' (a remark made upon seeing a green table, no red chair being present or having been mentioned). When this habit is well established, the child sometimes produces the most far-fetched contrasts. This stage is mentioned here merely by way of anticipation; for it takes us beyond the period under discussion.

To return to phonemic matters, from the very beginning of the slow initial development (11th-21st), words which introduce a new sound have at first the character of loan-words. Thus a period of seven months follows upon the appearance of the vowel $u$ before a two-vowel system is established (22d; see below). Up to then $u$ remains a rare and 'foreign' sound (comparable e.g. to the nasal vowels of French loan-words in English); and it occurs at first only in words that have $/ \mathrm{u} /$ or $/ \mathrm{uw} /$ in English, whereas later it represents all mid and high vowels. Similarly, the first morpheme of the structure CVC, bas, does not automatically transform the initial prosodic system, which renders English CVC as consonant + short vowel, and English CV as consonant + long vowel. ${ }^{18}$ It is only after a large number of new words of the type CVC have been adopted that an old form like $b a$ 'bottle' changes to $b a z$ (22d). Even then, $b a$ 'bang, shut' remains unaltered for no less than 18 months, and the demonstrative $z a$ continues to be used side by side with $z a t$ 'that'; for from almost every stage of the development some of the most frequently used morphemes

\footnotetext{
${ }^{17}$ In her play (22d-28th), she uses anything for any purpose. She will, for example, rock a toothbrush to sleep, put a shoe in the oven to bake, and offer food to anything under the sun-a process which reaches its logical limit with the gesture of offering bacon to the eggs. This is not to be confused with a later stage of play when an avowed pretense is made that certain things REPRESENT other objects or beings.

${ }^{18}$ In the initial stage of many children's speech, the universal rule that morphemes are composed of no more than two different phonemes persists even when 5 or 6 phonemes have been acquired, so that this prosodic system is retained much longer than in Joan's speech. The form $d a$ ' 'doll', by the way, is no exception, since English final $l$ appears as a vocalic element in the child's language; cf. the secton on the liquids below.
} 
are retained without change-just like the archaic forms ${ }^{19}$ that can be traced in most languages whose history is known over a certain length of time.

After the 21st month Joan's preference for closed syllables asserts itself, and the type CVC outnumbers all others for almost a year. The structure CVCV is at first often reduced to CVC, as in daba 'grandpa' (22d), which after a day or two assumes the permanent form dap. English clusters are represented by a single phoneme, except in the case of final ts for Engl. [ts, dz, č, ̌̉, ks, gz]. Nursery words of the conventional reduplicated type are rare in the child's speech since she has never been taught any such terms, except for $b a^{\prime} b a$ (which takes over some of the functions of the earlier at 'out') and ma'mma (24th), which first occurs (22d) in the compounds $m a^{\prime} m m a-b u$ ' 'mother bear' and $m a$ ' $m m a-d a^{\prime} t$ 'm. duck' (appearing in picture books).

Since French and Norwegian are frequently spoken in the household and used to address the child (though less often than English), she acquires at an early date a large passive vocabulary, and is able to follow fairly complicated directions, in these languages. But when her general active vocabulary begins to increase ( $22 \mathrm{~d}$ ff.), almost only English words are adopted; and during the subsequent year no more than two dozen French and Norwegian words appear in everyday usage (although a good many more are employed occasionally), as compared to thousands of English terms. Normally Joan responds in English when addressed in French or Norwegian. Morphologically and syntactically her language is entirely modelled on English, and phonologically (as regards the development beyond the initial universal stage of infant language) it is based on her mother's General American speech. ${ }^{20}$ Of the morphemes listed above only a few were used to represent French words, such as ba 'balle', bas 'poche', bat 'boîte'. Her first Norwegian words appear somewhat later (22d): mat for Norw. mat [ma·t] 'food', dus for gris 'pig', and zuwa for sove 'sleep'. Incidentally, $z u w a$ is the only word of her language in which $w$ follows upon $u$; it later changes to suwa (24th), then to suva (36th).

During a five-week period beginning early in the $22 \mathrm{~d}$ month the child's vocabulary increases from 30 morphemes to 150 , i.e., if allowance is made for homonyms, from 40 words to over 200 . Only 28 of these morphemes contain one or

19 They are, however, not often recognized as such. To give an example at random, French forms like époux, jaloux, etc. (which have not undergone the general change from OFr. [u], i.e. orthographic ou, to Mod. Fr. [ö], orthogr. eu) may simply be regarded as survivals. Thus there would be no need for most of the elaborate explanations offered in historical grammars to account for these and similar exceptions from a given diachronic development.

${ }^{20}$ It is well to be wary of attributing individual particularities in an infant's pronunciation to dialectal or other special influences. In Joan's language, e.g., the high vowel $u$ resembled at first a narrow Scandinavian 0 -sound, as in Norw., Swed. sol [sw·1] 'sun', Swed.

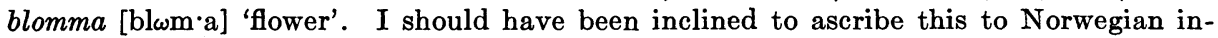
fluence (even though short [ $\omega]$ does not occur in Norwegian) if I had not heard the identical sound in the speech of small children who have certainly never heard a word of Scandinavian. Since this sound changes, by almost imperceptible stages, to [u], the transcription $u$ has been used from the beginning. It is to be noted that Joan's $u$ and $u \cdot$ differ solely in quantity throughout the period described in this paper. 
several newly adopted sounds, namely 13 terms with initial $h$ given in the comprehensive list below; 6 with final $z$ (for Engl. intervocalic liquid and intervocalic $t$ ), cf. maz '(to)morrow' (which soon changes to maza), haz > haza 'Harry', baz 'bottle, butter', buz 'a picture of Napoleon', daz (> taz [24th]) 'color', waz 'water'; and 9 with final $b$ or $d$ (which appear as allophones of $-m$ and $-n$ in words beginning with consonants or $h u-$ ), i.e. bub 'broom', bud 'spoon', $d a b$ 'jam', dud 'train', fub 'swim', wub 'room', wud 'rain', hub 'home', hud for Norw. [hun] 'dog'. ${ }^{21}$ All other morphemes that appear during this period are composed of the previously acquired 9 phonemes, namely (1) $p / b$ for Engl. [p, b, v-], (2) $t / d$ for E [t, d, k, g, č-, ǰ-], (3) $f$ for E [f, hw-, sw-], [- $\theta]$ and [- $ð]$ after labials, and [-v], (4) $s / z$ for $\mathrm{E}[\mathrm{s}, \breve{s}, \mathrm{z}, \mathrm{z}],[\theta]$ and $[\gamma]$ initially and after dentals,

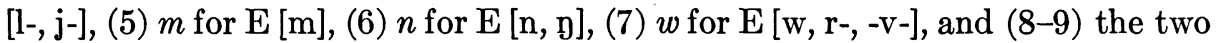
vowel phonemes. Thus the utilization of all theoretically possible combinations of these 9 phonemes rises, for monosyllables, from $26 \%$ to about $86 \%{ }^{22}$ Cf. the following list.

$b a$ 'shut' $\quad d a$ 'down' (later daw) $\quad n a$ '(French) non' $z a$ 'that' (These are the only four forms with stressed short vowels in open syllables. Such vowels are long in all other words in this list, while closed syllables invariably have short vowels. It will therefore not be necessary to indicate the quantity by means of symbols.)

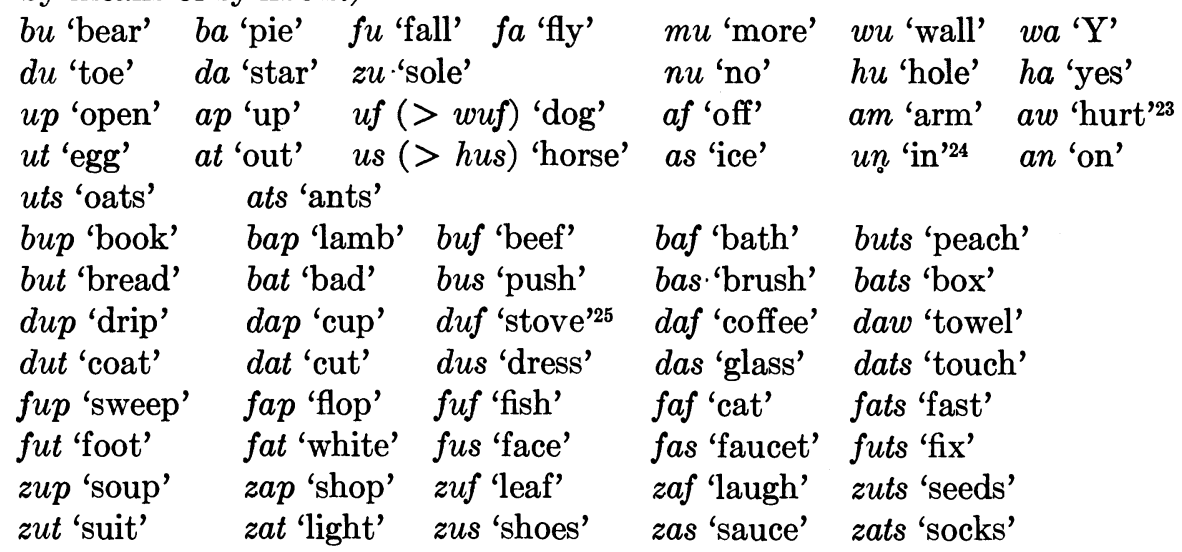

${ }^{21} h$ and $-z$ represent additions to the phoneme system, $-b$ and $-d$ do not-as would appear clearly in a phonemic transcription employing one symbol for each of the allophone pairs, $p / b, t / d, m / b, n / d$, e.g. $\mathrm{P}, \mathrm{T}, \mathrm{M}, \mathrm{N}$. The phonetic directions would merely have to state that $P$ and $T$ are voiced in non-final position, and that non-initial $M$ and $N$ are denasalized after oral consonants and $h u$-.

22 This percentage would be even higher if allowance were made for theoretical combinations which could not possibly represent any English words. As a matter of fact, even some of these are utilized later; cf. $m u f$, which is used as the name of a dress in $m u f-d u s$ (23d).

${ }^{23}$ This is of course an interjection. Its pronunciation indicates that it has the structure VC; later it changes to awa, which, like the forms dawa, fawa, etc. listed below, quite clearly has an open juncture between the first $a$ and the $w$.

${ }^{24}$ Final $-n$ in $u n$ and $-m$ in $a m$ ' $M$ ' are retained until the 25 th month, when they change to $-n$ and $-m$.

${ }^{25} f$ for Engl. final $v$ occurs only during this period; it is later replaed by $w$ (zero aftr $u$ ), as in $z a w$ 'love', $d u$ 'stove' (23d). 


\begin{tabular}{|c|c|c|c|c|}
\hline \multirow{3}{*}{ mut 'milk' } & map 'mop' & maf 'mouth' & mun 'moon' & man 'man' \\
\hline & mat 'mud' & mas 'mouse' & muts 'mix' & mats 'match' \\
\hline & nap 'snap' & nuf 'sniff' & naf 'knife' & nam 'thumb' \\
\hline nut 'neat' & nat 'night' & nus 'nurse' & nas 'nice' & nan 'lion' \\
\hline nats ${ }^{26}$ 'lunch' & wap 'wipe' & wuf 'roof' & waf 'rough' & wuts 'weeds' \\
\hline wut 'wet' & wat 'rock' & wus 'rose' & was 'wash' & wats 'watch' \\
\hline hup 'help'27 & hap 'frog' (' & 'hop') & ham 'ham' & han 'hand' \\
\hline hut 'head' & hat 'hot' & hus 'hose' & has 'house' & hats 'high-chair' \\
\hline
\end{tabular}

There are two forms consisting of a single phoneme, $u$ 'ear' and $a$ 'eye'; two of the structure VCC, ${ }^{28}$ namely aps 'apple sauce' (which a few weeks later changes to $a b u s$ ) and daws 'trousers' (later dawzas); ${ }^{29}$ but not a single word of the type VCV.

Of the 20 dissyllabic morphemes used in this period, one has the structure CVV, i.e. zua 'liver', later also 'little' (see the section on the liquids below); all others are of the type CVCV or CVCVC, cf. $^{30}$ dawa 'tower, cover', fawa 'flower', bawa ${ }^{31}$ 'bottom', hama 'hammer', bubu 'baby', budu (for earlier but) 'pudding', dubu 'table', zudu 'sugar', nudu 'noodle(-soup), naked', the names $d u d u$ and mamma quoted above, $d a b u$ ' $\mathrm{W}$ ' (early $22 \mathrm{~d}$; the first morpheme composed of more than three different phonemes), badu (replacing nana) 'banana', buda' 'put on', wabut (with five different phonemes) 'rabbit', babus '(a picture of) puppies', nabud 'napkin', nadaw 'night gown', hamaz > hamuz 'cat food' ('hamburger'). Finally, there must be added the curious name $b u b-b u$ (taken from the refrain [bum bum] of a Norwegian nursery rhyme) which Joan chooses for herself; the compound han-bu 'hand bag'; and the first compound the child forms of her own accord: faf-daw 'Fuff towel' (a towel with the picture of a cat). From now on unstressed syllables are, as a rule, no longer completely disregarded, but English post-tonic syllabics, including syllabic liquids and nasals, are rendered as $u$ ( $a$ after $w, u$, or $z$ ).

Only one meaning has generally been given for each of the morphemes listed. The following examples will indicate the large number of homonyms represented by some of them.

bat 'black, pat, bark, spot, block, pocket, bought, button, bent, bite'

${ }^{26}$ Of the forms with initial $n$ by assimilation or by transference, only nam 'thumb' survives for a considerable time; nats and nan are soon replaced by zats and zad.

${ }^{27}$ This word survives for twenty months, although after the end of this period Engl. $[\varepsilon l]$ is rendered as $a w$, as in bawt 'belt'.

${ }^{28}$ Except for the morphemes with final ts listed so far. Plural forms in -ts, such as wuts 'weeds', zuts 'seeds' (i.e. inedible parts of one's food), have been quoted only if the singular is rare or does not occur in the child's speech. -ts for Eng. -st, by the way, appears only in the two forms fats 'fast' and wuts 'waste(-basket)'.

${ }^{29}$ This is the first appearance of $a w$ before consonant. has 'house', maf 'mouth', mas 'mouse' are retained for two months before they become haws, etc.

${ }^{30}$ The word accent will henceforth be marked only if it is not on the initial syllable.

${ }^{31}$ With $-w$ - in place of $-z-$. Assimilation of this type is considered an important characteristic of infant speech by Wundt, Grammont, and Ronjat (18-20; cf. the literature quoted there). The only other instances in Joan's language are the words bup and fuf quoted above, and the regular use (for over two years) of $f$ for Engl. th after labials, ef. baf 'bath', maf 'mouth', as over against dus 'tooth', das 'cloth'. 
but 'brick, pig, bead, bed, break, board, boat, bird, put, boot'

$b u$ 'boy, pea, beer, bare, pear, ball, blow, bowl, blue'

$n u$ 'new, knee, near, nail, no'

These examples illustrate, furthermore, the regular correspondence between the child's two vowels and the accented syllabics of English, i.e. $a=$ Engl. $[æ, \mathrm{a}, \rho, \Lambda],[\varepsilon]$ before Engl. nasal or liquid, [a $\iota], u=$ Engl. $[\iota, \mathrm{i} \cdot],[\varepsilon]$ before stop or spirant, [e', or], [ol] after Engl. initial labials, [o $\left., \partial^{\cdot}, v, u+, \iota \iota, \iota u\right]$.

The child's phoneme system and the phonemic structure of English are obviously non-congruent. That is to say, not only does almost every unit of the child's system render several English phonemes, as might be expected, but, conversely, the phonetic variants of a given English unit may appear as different phonemes in the child's language. In the consonant system this fact appears most clearly in the representation of the English liquids. For apart from the 6 examples with $z$ for Engl. intervocalic liquid, which survive for 20 months, Engl. $l$ and $r$ are from now on (23d-42d) consistently represented as follows.

$z=$ Engl. pre-tonic (clear) $l$, as in $z u f$ 'leaf', zudu 'lady', zat 'like, lock', zap 'lap', buza'd 'belong'.

$z$, by the way, also renders French (uvular) $r$, as in $z a w$ 'Raoul'; mazua' 'Montréal', i.e. [mõre $\alpha^{\prime}$ l] in French-not French Canadian-pronunciation; za dad (24th) 'prends garde' (Engl. pr- would be represented as a simple labial stop).

$w=(1)$ Engl. post-tonic (dark) $l$ after [ $\varepsilon, \mathfrak{x}, \Lambda]$; cf. waw 'well', maw 'smell', baw 'bell', bawt 'belt', dawa 'jelly', zawa 'yellow', saw (27th) 'shell, shall', dawat 'gallant', daw 'gull'; and after Engl. [wa], as in wawas 'Wallace'.

$w=(2)$ Engl. initial $r$, or intervocalic $r$ after [a, æ, $\varepsilon$ ], as in wat 'right', wabu 'rubber', wud 'ring', wuts 'reach'; sawa (24th) 'sorry', mawa 'Mary, marry', dawa 'carry, cherry'.

zero $=(1)$ Engl. final $r$ and $r$ in clusters; cf. $f a$ 'far', $d u$ 'door', but 'bread', munu 'morning', dat 'dark'.

zero = (2) Engl. $l$ after [0], as in $a$ 'all', $d a$ 'doll', $t a$ (24th) 'call', $t a \cdot d$ (27th) 'called' (after Engl. initial labials: $b u$ 'ball', $f u$ 'fall', $w u$ 'wall'); after [a [], as in $f a$ 'while'; after [av], as in aw 'owl'; and after consonants, cf. fa 'fly'.

Both English liquids appear of course as zero after all the vowels which are represented by $u$ in the child's speech; cf. $p u$ (24th) 'spill, peel, pail, pole, pearl, pull, pool, spoil'; pua (26th) 'paring, pouring, purring, pillow, peeler, pulling', mua 'mirror', wua 'worry', $u a$ 'early'. (In all these forms final $a$-for $u$ by dissimilation-represents the unstressed syllable.)

The consonant correspondences given so far remain unchanged for 10 months, except for the appearance of a phonemic distinction between voiced and voiceless stops. This process is inseparably connected with a simultaneous vocalic development. It passes through the following 5 stages.

(1) $a$ appears (23d) in stressed closed syllables for Engl. [a], i.e. the General American syllabic of part, pot, pod; cf. da·p 'top' (as over against dap 'cup, cap'), $d a \cdot t$ 'dark', $n a \cdot p$ 'knob'. ${ }^{32}$

32 That is to say, $a \cdot$ represents Engl. [a] in all newly acquired words. It has not yet spread to all old morphemes when stage (2) sets in. In stressed open syllables $a$ has of course been long from the beginning, except for the four forms, $b a, d a, n a, z a$, quoted above. 
(2) $a$ and $u$ are used (24th) to render all Engl. accented syllabics, except [l] and [v], before Engl. voiced stops and spirants; cf. ba't 'bad' (but bat 'back'), ma't 'mud' (nat 'nut'), wu't 'red, wade' (wut 'wet', wuts 'waste'), bu't 'bead' (but 'beat'), nu's 'nose' (dut 'goat'), fu't 'food' (dup 'coop'). The child's language thus turns the English non-distinctive variation of vowel quantity into a phonemic difference, while still disregarding the distinction between Engl. $/ p, t, k, s /$ and $/ b, d, g, z /$ - type of phenomenon that can often be observed in the speech of foreigners. This vowel lengthening process quickly affects the whole vocabulary, but after barely three weeks it is partly reversed in stage (3b).

(3) Three changes occur simultaneously. (3a) Final $b$ and $d$ are employed (instead of $-p,-t$, as heretofore) to represent Engl. voiced stops. This introduces two new phonemes: whereas previously only two of the three labials [p, b, m] or of the three dentals $[t, d, n]$ could be distinguished in any given position, it is now possible to differentiate all three, though only when they occur as finals in words with initial nasal or vowel or $h a-$; cf. $m u \cdot t$ 'meat', $m u \cdot d$ 'maid', $m u \cdot n$ 'moon', $u \cdot t$ 'eat, eight', $u \cdot d$ 'old', $u \cdot n$ 'own', hat 'hat', had 'hug', han 'hen'. The phonemic oppositions concerned are neutralized in all other positions, i.e. /p-b/ and $/ \mathrm{t}-\mathrm{d} /$ in non-final position (cf. $d u$ 'do, go, tea, toe', $b u \cdot d u$ 'bacon, broken, birdie'), /b-m/ and /d-n/ in words with initial oral consonant or hu- (as in $w u b$ 'rib, rim', bud 'big, bin', $z a \cdot d$ 'yard, long', babu 'puppy, bubble, plumber', hud for 'hood' and for Norw. hun 'she').

Concomitantly, $-z$ (replacing $-s$ ) is now used for Engl. final [z, ž], as in $n u \cdot z$ 'nose', $h u \cdot z$ 'hose', $w u \cdot z$ 'rouge', a change which does not involve any addition to the phoneme inventory since $-z$ had appeared previously (cf. note 21). Final or medial $z$ for Engl. intervocalic $t$ is retained; and $-z$ - is now employed also for Engl. intervocalic /j/, as in faza 'fire'.

(3b) $a$ for Engl. [ $[\Lambda]$ and $u$ for Engl. [ $\varepsilon$ ], which had become long during stage (2), are shortened again as in wud (<wu't) 'red', mad (< ma't) 'mud'.

(3c) $u$ for Engl. [iं, e', $\left.o^{*}, \partial^{\cdot}, u^{*}\right]$, which had up to now remained short before finals representing Engl. voiceless consonants, becomes $u$ in all stressed syllables; cf. $d u \cdot s$ 'grease, goose', $z u \cdot t$ 'lake', du't 'coat', hu't 'hurt'.

To sum up, the changes 1,2 , and $3 \mathrm{~b}-\mathrm{c}$ constitute an extension of phonemic vowel quantity (which had previously applied only to stressed final open syllables, cf. $b a$ 'shut', $b a$ ' 'pie') and result in the following correspondences.

$a=$ Engl. [æ,,$\left.a_{\imath}\right]$ before voiceless consonants; [ $\left.\varepsilon\right]$ before Engl. liquids or nasals or intervocalic $t ; 3[\Lambda]$ in any position.

$a \cdot=$ Engl. [æ,, a $a$ ] before voiced consonants; [a] in any stressed syllable.

$u=$ Engl. $[\varepsilon]$ before stop or spirant; $[\iota, v]$ in any position.

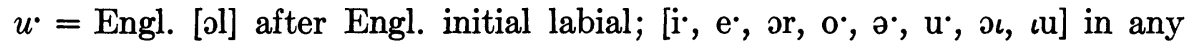
stressed syllable.

This system of 4 distinctive syllabics remains unaltered for 9 months; and only one phonetic change is to be recorded for this period (24th-33d). Beginning with the word sit 'sit', $\iota$ appears as an allophone of short $u$ before dentals in accented syllables (25th). Accordingly, fut 'foot', dud 'good', bus 'bush', futs

${ }^{33}$ Cf. baza 'better', faza sweater', $z a z u$ 'letter' (with $u$ after $z$, which appears during the 27th month). 
'fix', $u d z$ 'edge', duza 'dizzy' change to $f_{\iota t}$, $d \iota d$, etc., while $f u p$ 'whip', fub 'swim', wuf 'wolf', etc. retain $u$. A phonemic opposition $/ \mathrm{u}-\iota /$ is not established until the 36 th month.

(4) The oppositions $/ \mathrm{p}-\mathrm{b} / \mathrm{h} / \mathrm{t}-\mathrm{d} /$, and $/ \mathrm{s}-\mathrm{z} /$ cease to be neutralized in initial position (25th), so that is now possible to distinguish pats 'pencil, pants, plants' from bats 'bench, box, blocks', $t u \cdot d$ 'cold, cord, toad, stone, turn, clean, queen, train, chain' from $d u \cdot d$ 'green, Joan', sa'd 'side, sign, slide, sand, song' from $z a \cdot d$ 'yard, lawn, lion, line, (a)long', $p u \cdot b u$ 'people, paper, purple' from $b u \cdot b u$ 'baby', ta'budz 'cabbage' from $d a \cdot b u d z$ 'garbage', $s a \cdot d u$ 'shadow' from $z a \cdot d u$ 'ladder', and many other forms which previously were homonyms.

The changes described under (3a) and (4) are exceedingly rapid and differ from all previous and most later ones in that they leave no residue whatsoever.

(5) The oppositions listed under (4) cease to be neutralized in medial position also (27th); cf. papu 'puppy' ( $p a b u$ 'probably'), nu'tu 'naked' ( $n u \cdot d u$ 'needle'), $d u \cdot s a$ 'grocer' ( $d u \cdot z u$ 'daisy'). Note that $t$ - represents Engl. / $\mathrm{k} /$ or $/ \check{c} /$ since $z$ continues to render Engl. intervocalic $t$, as in zazu 'letter' (27th), $z u \cdot z u$ 'later' (28th). This final stage in the process of introducing the phonemic distinction between voiced and voiceless consonants, which is separated from the previous stages by a lengthy interval, takes no less than three months to spread to a major portion of the previously acquired vocabulary.

Simultaneously with the change recorded under (5) there appears the third consonant cluster (after $-t s$ and $-d z$ ) of the child's language, namely final $-s t$. For a period of two or three weeks this produces a considerable number of hypernormalisms. For when $p u \cdot s$ 'post' changes to pu'st (27th), a number of forms with $-s$ for Engl. $-s$ also change temporarily to $-s t$. This phenomenon has frequently been observed in infant language, but in general it does not play an important part in Joan's linguistic development.

The increased use of plurals and the gradual appearance of possessive and 3dperson forms bring into use the further final clusters $-p s,-f s,-b z,-m z,-n z$. For this (27th-30th) is a period of rapid morphological and syntactical development. In swift succession there appear prepositions, demonstratives, auxiliaries, articles, preterite forms, conjunctions, and possessive and personal pronouns. It would seem normal that the first grammatical forms to occur in the language of an English-speaking ehild should be those with an $-s /-z$ morpheme. But it is of course impossible to make any general statement about morphological development in infant speech since it is entirely dependent on the morphophonemic structure of the particular language that is being learned. And as regards syntax, only one observation can be made that holds good universally, namely that it begins with complete anarchy. Even when Joan's utterances are as yet restricted to two morphemes (early 22d), there occur such contradictory formations as hat dap 'Grandfather's hat', pat zu 'Pat's shoe', mut-daf 'milk (for) coffee', i.e. 'coffee cream', fut-zas 'food saucer', i.e. 'a small plate for food'; and shortly thereafter longer statements of an erratic order can be recorded, cf. as haza waz 'Harry's ice water', buf mamma faf 'beef mother (gives to the) cat', baba nabud wut 'gone (are the) red napkins'. By the end of the $33 \mathrm{~d}$ month, however, the syntax of Joan's speech, in which long compound sentences have 
now become quite frequent, is generally in conformity with standard English, and so, on the whole, is the morphology (except for some analogical weak preterite forms).

As to the number of phonemes and words, the child's language has now (30th) 524 morphemes ( $=$ well over 1000 words), namely 366 monosyllabic (excluding inflected forms ending in consonant $+s$ ) and 158 polysyllabic ones. The following list of morphemes with initial $t+\mathrm{VC}$ may serve as a sample.

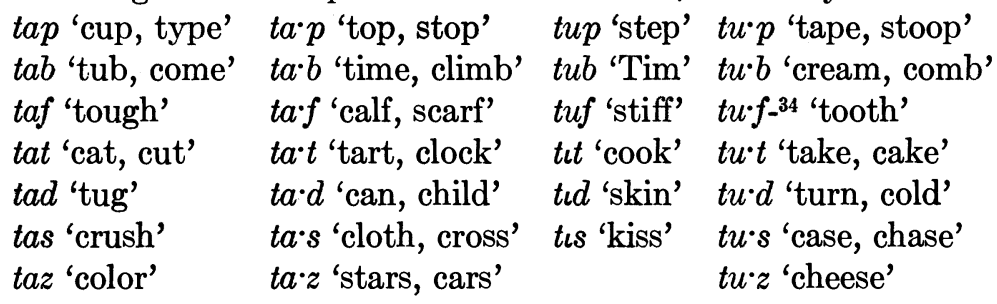

taw 'tell, towel'

This represents a utilization of $96 \%$ of all possible phoneme combinations. The corresponding figures for the whole vocabulary are: morphemes of the type CVC, $65 \%$; all monosyllables, $62 \%$; type CVCV, $19 \%$. There are only 32 examples of the structure $\mathrm{CVCVC}(\mathrm{C})$, and (barring compounds) only 15 forms of more than two syllables, such as tawafud 'telephone', dawaput 'davenport', satupud 'centipede', u'putats 'apricots', maduzu.d 'magazine', suduwı't 'cigarette', tasatu' $t$ 'street crossing' (literary 'cross the street'). Note that this last word is not, phonologically speaking, a compound in the child's language; cf. on the other hand $t a \cdot$ 'fa-tu't $t$ 'coffee cake', $u^{\prime}-p u^{\prime} d$ 'air-plane', $t a \cdot{ }^{\prime} p$-tu' 'cocktail' (with $p$ by dissimilation; the cluster $p t$ does not occur within a single morpheme).

The phonological changes which occur during the remainder of the third year may be briefly summarized as follows.

(1) The neutralization of the oppositions $/ \mathrm{b}-\mathrm{m} /$ and $/ \mathrm{d}-\mathrm{n} /$ after oral consonants disappears (30th-33d), first in final, then in medial position; and, simultaneously, ` appears in unstressed closed syllables (before dentals only, as heretofore); cf. u'pın 'apron', fa'ma 'farmer', sa'mın 'salmon' (for earlier $u \cdot p u d, f a \cdot b a, s a \cdot b u d)$. Nasals appear in clusters, as in antu (<atu) 'uncle', zasins pu't 'licence plate'.

(2) Three phonemes and one new phoneme combination enter the language (33d-36th), namely (a) $\iota^{35}$ for Engl. [iं, e'], as in $d \iota^{\circ}$ 'day', $w \iota^{\bullet} d{ }^{\prime}$ 'read' ( $<d u$,

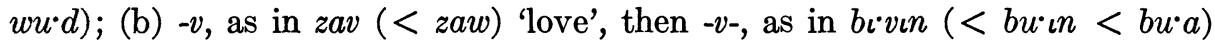
'bathing', and finally $v$-, as in $v \iota n d u(<b \iota d u)$ 'vinegar'; (c) the phonemic opposition $/ \mathrm{u}-\iota /$ appears in unstressed open syllables (but is neutralized in all other

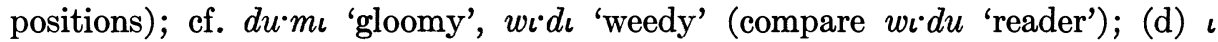
appears after $a$, as in fal 'fly, why', baıt 'bite', taıt 'kite'.

The further development during the fourth year need not be described here since it proceeds according to the same principles as heretofore. But it may be mentioned that during a period of seven weeks (42d-44th) there appear no less than five new vowel sounds (all of which occur as allophones before they become

${ }^{34}$ Occurs only in $t u \cdot f$-bas 'tooth brush' (with $f$ for $s$ by assimilation).

${ }^{35}$ Pronounced exactly as the vowel in Swed., Norw. le 'laugh'; cf. note 20. 
additions to the phoneme system), i.e., in chronological order, $e, \varepsilon, o, \jmath, \mathscr{X}$. Shortly afterwards all the child's vowels begin to acquire for the first time the exact phonetic characteristics of the corresponding English sounds. Thus $\bullet$ is raised until it is identical with the syllabic of English meet, while $e$ and $o$ are lengthened and sometimes pronounced with a glide toward $[\iota]$ and $[v]$.

To sum up, the analysis appears to show that the development of a child's language may, to some extent, serve as a miniature working-model (on a greatly compressed time-scale) of diachronic linguistics. Needless to say, this does not mean that infant speech recapitulates the history of the parents' language or of human speech in general. But the chronological sequence of its structural patterns enables us to observe, within the space of a few days or weeks, such phenomena as the transformation of phonetic variants into phonemes, the treatment of loan-words, the appearance of hypernormalisms, and the survival of forms which have remained exempt from change. 